\title{
Soft Computing Based Tuning of PI Controller With Cuckoo Search Optimization For Level Control of Hopper Tank System
}

Vinothkumar c ( $\sim$ vino83pc@gmail.com )

Sathyabama Institute of Science and Technology

C Esakkiappan

Panimalar Engineering College

\section{Research Article}

Keywords: PI controller, FOPDT, Hopper Tank, Servo Regulatory Response, Performance Indices, Cuckoo Search Optimization, Soft Computing

Posted Date: October 18th, 2021

DOI: https://doi.org/10.21203/rs.3.rs-920228/v1

License: (c) (i) This work is licensed under a Creative Commons Attribution 4.0 International License.

Read Full License 


\title{
Soft Computing based Tuning of PI Controller with Cuckoo Search Optimization for Level Control of Hopper Tank System
}

\author{
Vinothkumar $\mathbf{C}^{1^{*}}$ and Esakkiappan $\mathbf{C}^{2}$ \\ ${ }^{1}$ Research Scholar, Dept. of EIE, Sathyabama Institute of Science and Technology \\ ${ }^{2}$ Professor and Head, Dept. of EIE, Panimalar Engineering College, Chennai, India \\ *Corresponding Author Email: vino83pc@gmail.com
}

\begin{abstract}
The paper work focuses on soft computing and Conventional tuning approach to design of PI controller, which provides a better sustainable performance for a nonlinear hopper tank system which is used in Wastewater treatment applications. The system processes the combination of a conical and cylindrical tank for providing Multi-region based mathematical modelling to obtain the first order with delay time (FOPDT) process transfer function model. The Ziegler Nichols, Cohen-coon, Tyreus Luben, CHR (Chien, Hrones, and Reswick), IMC (Internal Model Control), Direct Synthesis, FOPI( Fractional Order PI) Conventional tuning formulae and Cuckoo Search Optimization (CSO) algorithm are used to optimize the servo regulatory responses of PI controller. The integral and proportional gain of the PI controller is said to produce the fastest settling time and reduces the error using performance indices and achieves Liquid Level control in hopper tank. Comparison is made for the various conventional controller tuning methods with Cuckoo Search Optimization tuning responses and identified to CSO-PI method offers enhanced Optimized Performance while comparing to Conventional tuning methods for a region based system.
\end{abstract}

\section{Keywords: PI controller, FOPDT, Hopper Tank, Servo Regulatory Response, Performance Indices, Cuckoo Search Optimization, Soft Computing}

\section{Introduction:}

In recent days the industrial process mainly uses Proportional Integral Derivate controllers to control process parameters. The major role of these parameters is to maintain the effectiveness and Environmental disturbance that occurs during the operation. The controller gain of the three main constraints like gain of proportional, gain of Integral \& gain of derivative controller is usually a constant value based on the tuning parameters. It may have uncertainty while dealing with the plant operation, but it can reduce by tuning the gain values. The control of water level, pressure, flow and temperature is essential to maintain using these parameters. The error due can be reduced using the performance indicators like Integral of Square Error (ISE), Integral of Absolute Error (IAE), Integral -Time Absolute Error (ITAE). All these practices are being implemented in the Hopper tank system which provides the advantages of easy flow of materials and having large storage capacity.

The research framework carried out by different researchers with nonlinear processes and their controller techniques were discussed. Dhanalakshmi, R et. al[1] worked on real time implementation of various control techniques using matlab toolboxes for analysis of its parameters. Vadivazhagi, S et.al[2] introduced the stable operating region of the first order system using the process reaction method. Kala, $\mathrm{H}$ et.al[3] developed the transfer function for region based operating systems to make the comparison between the Direct Synthesis-PI control \& Model Predictive-PI control (MPC). Anand, S et.al[4] done their research work in identifying the FOPTD 
model for a conical tank system and verified their performance of adaptive PI controller by implementing using MATLAB software. Saravanakumar, G et.al [5] proposed an internal model based optimum controller to obtain a good servo regulatory response. Sarif, B. Mabu et.al [6] have done their work on various PID controllers to obtain suitable performances indices and time integral criteria for the superheated steam temperature system. Marshiana, D et.al [7] developed the Fractional Order Proportional Integral Controller using the down order calculus method for a conical tank system. The nonlinear system designed performed by digital algorithm [13] based dead beat controller provides better performance when compared with the analogy type PID algorithm. It is stated that many of the chemical industries [14] uses conical or hopper tank system for easy flow of materials without any loss. Venkatesan, M et.al [8] offered a relative study on the characteristics and performances of Sliding Mode controller using Sliding Mode Luenberger observer.

Ravi, V. R et.al [9] proposed a multivariable process based PID controller design for an interacting two first order conical tank system to determine its effectiveness on its operating ranges. The above model was compared with of Gain Scheduling Adaptive Controller over GA tuned multiregional PI controller was featured [10]. Optimization of the Genetic algorithm [11] based linear model predictive algorithm approach used for a conical interacting system with 2 tank model was validated all the way through simulated result. The decentralized PI- Controller combined with the decouplers used for the stability analysis with TCTILS to minimize the interactivity property of the conical process tank. Anandanatarajan, R et.al [15] analyzed that the variations in the system parameters will affect the controller performance which can be controlled using the tuning parameters and the gain scheduling method is best suited for this technique. Kesavan et.al[16] worked on the real-time execution of a PID controller with conical region of hopper tank and optimized the performance with the error criteria for various tuning methods. Murugananthan, $\mathrm{V}$ et.al[17] highlighted the performance of modified IMC with other techniques using error criterion and time domain analysis for a nonlinear hopper tank system. Gireesh, N et.al[18] discussed the tuning parameters of conventional PID controllers using different methods for a conical nonlinear system. The uncertainty of the process can be rectified by using these methods.

Durga Vivek et.al [19] states that the optimum PID process variable is achieved by cuckoo search algorithm for the second order with delay time process. Saeed Balochian et.al [20] states that the best suitable optimization technique is the cuckoo search method for identifying the optimal value in control of a water tank system. The merits of Sugeno type FLC with respect to the CSO method can obtain a rapid convergence were implemented. Meenakshi Kishnani et.al [21] implement the cuckoo algorithm for optimize the PID control parameter through levy flights and to reduce error the through its fitness function for a linear plant. Petchinathan Govidan [22] states that the performance identification for an automatic voltage regulatory system is done by optimization of PID parameters using PSO and CSO algorithms. Abdelaziz et al [23] found that the cuckoo search algorithm offers better performances related to the performance indices and settling times. The PI value obtained from CSO for Load frequency control provides better results when compared with the Conventional control method and Genetic algorithm. Marshiana et.al [24] develops PI parameters for a nonlinear system using the cuckoo search evolutionary algorithm. The advantage of this technique is because of its simplicity and cable to provide best results. 


\section{Experimental Schematic Setup and Modelling of Hopper Process Tank:}

A Mathematical model was developed for a hopper tank system which is said to be NonLinear. The construction of hopper process is the arrangement of both the bottom conical-section $\&$ top cylindrical-section. The top cylindrical region is being used for storage purpose by varying its height and bottom conical region is being used for discarding or removal of materials like liquids, solids and slurries. The mathematical illustration of the hopper process tank was done by means of the subsequent assumptions.

- Controlling variable is the liquid level of hopper tank

- Inlet flow to hopper tank is considered as manipulate variable

The transfer function model for the hopper tank is converted into a first categorize with dead time system by considering conditions of gain of process $\mathrm{K}_{\mathrm{g}}$, time constant $\tau$ and delay time of the process is $t_{d}$. Figure 1 demonstrates the plan view of the production of Hopper tank setup.

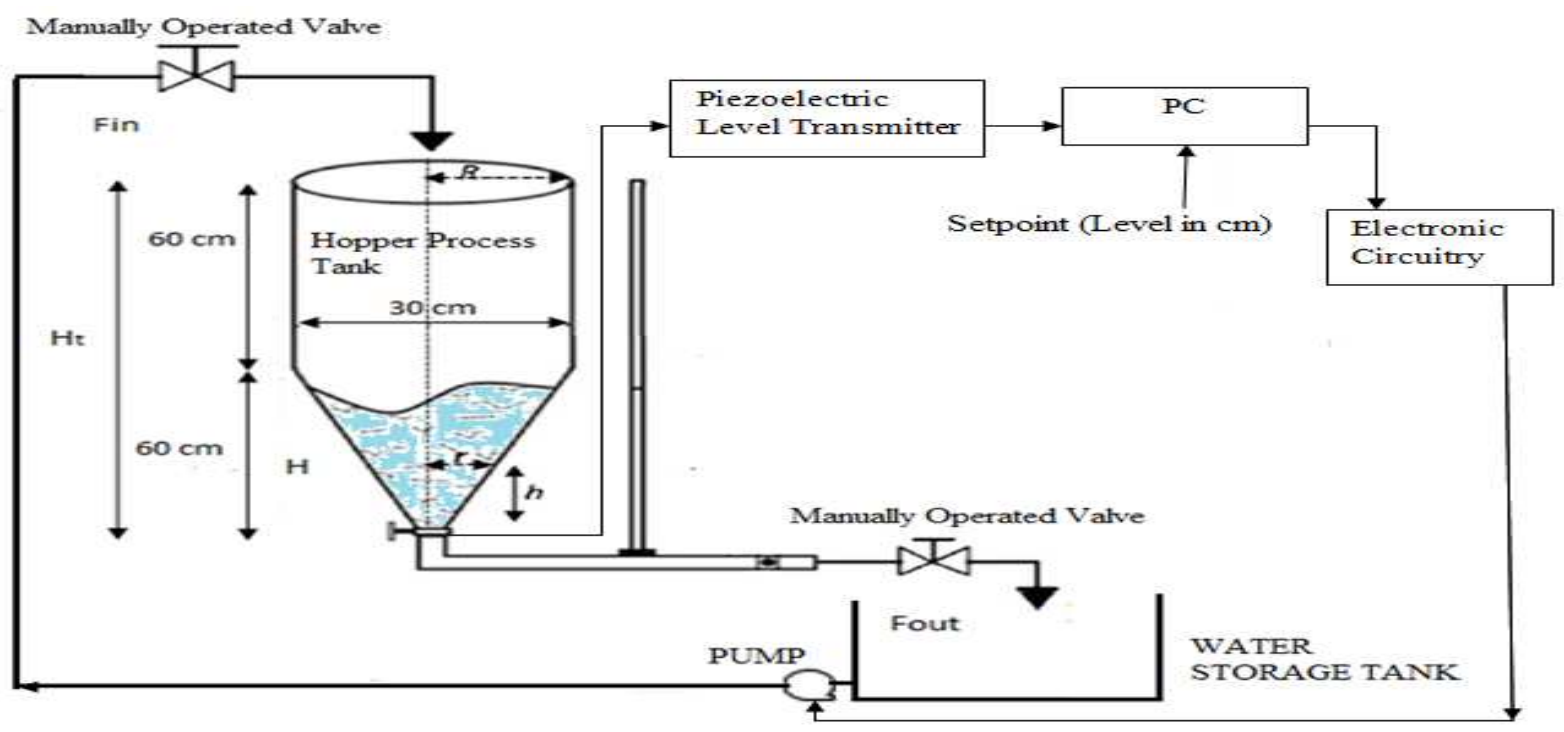

Figure 1. Outlook Feedback Arrangement of Hopper Process tank

Mass balance dynamic relationship of hopper tank conical section is

Inflow Rate-Outflow Rate $=$ Accumulation Rate

$$
F_{\text {in }}-F_{\text {out }}=\mathrm{A} \frac{d h}{d t}
$$

But, Outlet Flow Rate of the tank,

So Equation (1) becomes,

$$
\begin{gathered}
\mathrm{F}_{\text {out }}=\mathrm{a} \sqrt{2 \mathrm{gh}} \\
\mathrm{F}_{\text {out }}=\mathrm{b} \sqrt{\mathrm{h}}
\end{gathered}
$$

$$
F_{\text {in }}-b \sqrt{h}=A \frac{d h}{d t}
$$

Where $\mathrm{A}=$ Area at Height $\mathrm{h}(\mathrm{t})$, $\mathrm{a}=$ Bottom of tank outlet area, $\mathrm{b}=$ Constant, $\mathrm{g}=$ Acceleration due to gravity.

After Taking Linearization on equation (1) using partial differentiation,

$$
\partial \mathrm{F}_{\text {in }}-\frac{\mathrm{b}}{2 \sqrt{\mathrm{h}}} \partial \mathrm{h}=\mathrm{A} \frac{\mathrm{d}(\partial \mathrm{h})}{\mathrm{dt}}
$$


Applying Laplace transform and rearranging the equation (3) in the form of First order Equation,

$$
\mathrm{G}(\mathrm{s})=\frac{\partial \mathrm{h}}{\partial \mathrm{F}_{\mathrm{in}}}=\frac{\mathrm{K}_{\mathrm{g}}}{(\tau \mathrm{s}+1)}
$$

Therefore Transfer function of hopper tank with conical region is estimated to a first order mathematical model with dead time which changes with respect to the fluid level of process tank.

$$
\mathrm{G}(\mathrm{s})=\frac{\mathrm{K}}{(\tau \mathrm{s}+1)} \mathrm{e}^{-\mathrm{t}_{\mathrm{d}} \mathrm{s}}
$$

Here, $\quad K_{g}=2 \sqrt{h_{t}} / b ; \quad b=a \sqrt{ } 2 g ; \quad \tau=\left(2 A \sqrt{ } h_{t}\right) / b ; \tau=$ Time constant; $K_{g}=$ Gain of Process;

$\mathrm{h}_{\mathrm{t}}=$ Nominal level of process tank in $\mathrm{cm} ; \mathrm{A}=$ Area of process tank at nominal level $\mathrm{h}_{\mathrm{t}}$; $\mathrm{a}=$ Area of process tank bottom outlet ; $\mathrm{b}=$ Discharge constant;

The Hopper process tank Cylindrical Section is measured through speed of outflow straightforwardly relative to square root of fluid level $\&$ thus the model of cylindrical section is same as conical section except Area (A) of nominal height of tank is constant in cylindrical section. In any case, in conical section (A) is changed dependent on Nominal height $\mathrm{h}_{\mathrm{t}}$. The specifications of Hopper tank Process is mentioned in table 1.

Table 1: Specifications for Hopper tank Process

\begin{tabular}{|l|l|}
\hline \multicolumn{2}{|c|}{ Specifications for Hopper Tank } \\
\hline Total Height of Hopper tank $\left(\mathrm{H}_{\mathrm{t}}\right)$ & $120 \mathrm{~cm}$ \\
\hline Height of Conical Region $\left(\mathrm{H}_{\mathrm{con}}\right)$ & $60 \mathrm{~cm}$ \\
\hline Height of Cylindrical Region $\left(\mathrm{H}_{\mathrm{c}}\right)$ & $60 \mathrm{~cm}$ \\
\hline Topside Radius of the tank $(\mathrm{R})$ & $15 \mathrm{~cm}$ \\
\hline Tank outlet Radius $\left(\mathrm{r}_{\mathrm{b}}\right)$ & $1.25 \mathrm{~cm}$ \\
\hline Radius of tank at Nominal fluid level $(\mathrm{r})$ & $\mathrm{Rh}_{\mathrm{t}} / \mathrm{H}_{\mathrm{t}}$ \\
\hline Type of Level Transmitter & Piezoelectric Level Transmitter \\
\hline
\end{tabular}

Based on the single system identification, various regions are identified and its corresponding transfer function was developed and shown in Table 2.

\begin{tabular}{|c|c|c|}
\hline Regions & Level Operating Range $(\mathrm{cm})$ & Transfer function Model \\
\hline Region-1 & $0-15$ & $G_{1}(s)=\frac{0.03542}{(1.548 s+1)} e^{-0.9 s}$ \\
\hline Region-2 & $15-30$ & $G_{2}(s)=\frac{0.05013}{(8.9175 s+1)} e^{-4.8 s}$ \\
\hline Region-3 & $30-45$ & $G_{3}(s)=\frac{0.06170}{(24.572 s+1)} e^{-11.20 s}$ \\
\hline Region-4 & $45-60$ & $G_{4}(s)=\frac{0.07130}{(50.03 s+1)} e^{-19.50 s}$ \\
\hline Region-5 & $60-100$ & $G_{5}(s)=\frac{0.0920}{(65.029 s+1)} e^{-24.25 s}$ \\
\hline
\end{tabular}

Table:2 Representation of Region based Transfer Function 


\section{PI Controller Design with Conventional Tuning Techniques:}

The proportional Integral controller plays a major task in the control of the level process. Different types of tuning techniques are available for the level process hopper tank system. The $\mathrm{P}$ and I controller depends on the variation in gain of proportional $(\mathrm{Kp})$ and the gain of integral $\left(\mathrm{K}_{\mathrm{i}}\right)$ parameters. The mathematical expression of PI controller is specified as follows.

$$
C(t)=K_{p} E(t)+K_{i} \int E(t)
$$

The Ziegler Nichols, Cohen-coon, Tyreus Luben, CHR (Chien, Hrones, and Reswick), IMC (Internal Model Control), Direct Synthesis, and FOPI( Fractional Order PI) are the tuning methods implemented for the hopper tank system. In General the proportional controller produces offset error and it can be reduced by integral controller. The overshoot produced will be an acceptable range. The tuning methods are comparing among the simulation responses attained from the Matlab Simulink. The formulae used for calculating the gain parameters are exposed in Table 3.

Table:3 PI Controller Tuning Formulae

\begin{tabular}{|c|c|c|}
\hline \multirow{2}{*}{ Tuning Methods } & \multicolumn{2}{|c|}{ PI -Controller Tuning Formulae } \\
\cline { 2 - 3 } ZN-PI & $0.45 \mathrm{~K}_{\mathrm{u}}$ & $\mathbf{T}_{\mathbf{i}}$ \\
\hline CC-PI & $\frac{\tau}{\mathrm{Kt}_{\mathrm{d}}}\left[\frac{9}{10}+\frac{\mathrm{t}_{\mathrm{d}}}{12 \tau}\right]$ & $3.33 \mathrm{t}_{\mathrm{d}}$ \\
\hline TL-PI & $0.311 \mathrm{~K}_{\mathrm{u}}$ & $\mathrm{t}_{\mathrm{d}}\left[\frac{30+\left(3 t_{d} / \tau\right)}{9+\left(20 t_{d} / \tau\right)}\right]$ \\
\hline CHR-PI & $\frac{0.6 \tau}{\mathrm{Kt}}$ & $2.2 \mathrm{~K}_{\mathrm{u}}$ \\
\hline IMC-PI & $\frac{\tau}{\mathrm{K}\left(\lambda+\mathrm{t}_{\mathrm{d}}\right)}$ & $\tau$ \\
\hline DS-PI & $\frac{1 / \mathrm{K}}{2978}$ & $\tau$ \\
\hline FO-PI & $\frac{0.297}{\mathrm{~K}\left(\tau_{r}+0.000307\right)}$ & $\tau\left[\frac{\tau}{\left(\tau_{r}{ }^{2}-3.402 \tau_{r}+2.405\right)}\right]$ \\
\hline
\end{tabular}

\section{PI Controller Tuning with Cuckoo Search Optimization Technique:}

A cuckoo Search based Optimization finding is a new metaheuristic technique and has been presented by Yang and Deb in 2009[19]. CSO algorithm is executed dependent on powerful offspring freeloading activities of cuckoo variety in blend through Levy Flight performance of certain cuckoo birds [22]. These sorts of cuckoos used to lay their own eggs in other host bird nests via raising the shot at hatching through picking recently brought forth settles and disposing of setting up eggs. The host birds will deal among those eggs by means of accepting those eggs are their own. In some cases, few of the host birds may notice that the eggs are not their own \& afterward either it can through those eggs out or build the new nest in new place [19]. In view of this cuckoo hatching address, an Optimized solution is gained for the issue. The underlying populace taken is the number of cuckoos and their eggs. Cuckoo method of optimization will be carried out with following 3 supreme rules [22].

Rule 1: The cuckoo will lay its egg in a nest randomly and it will lay just each egg in turn. Rule 2: The egg with superior grade in the best nests will be taken to subsequent generations. 
Rule 3: The host bird will found the cuckoo's egg by the way of Probability $\mathrm{Pa} \in[0,1] \&$ Number of accessible nests for host is fixed.

Flow chart representation of CSO algorithm steps are explained in figure 2 with the help of these 3 idealized rules. While producing a new position $\mathrm{x}_{\mathrm{i}}(\mathrm{t}+1)$, Levy flight random walk stochastic condition[24] is performed by $x_{i}(t+1)=x_{i}(t)+S * E t$. Here Step size $S>0$ and generally $S$ $=1$. Much of the time, a random walk is being a Markov chain whose new position just relies upon the current position $\mathrm{x}_{\mathrm{i}}(\mathrm{t})$ and Et is normal standard levy distribution. CSO algorithm is the population -based algorithm and it is like PSO and the number of tuned parameters is not accurately like PSO and it is most probably more normal to adapt to a more extensive type of optimization issues [22].

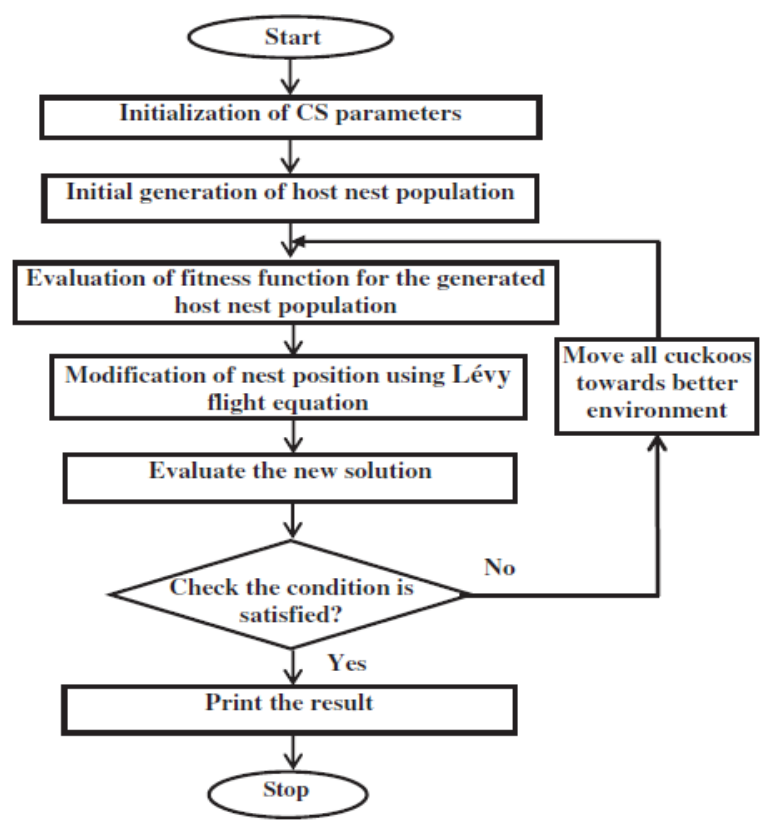

Figure 2. Flow Chart Representation of CSO Algorithm [23]

In this research work, the cuckoo search Optimization has been carried out for improving the performance of the PI controller [22]. The PI data sets considered for CS optimization are as per the following: Number of nests (Population) $n p=10$, Alien eggs Detection rate $\left(\mathrm{p}_{\mathrm{a}}\right)=0.25$, Total number of Iterations $=200$, No of parameters to be enhanced $\mathrm{n}=2(\mathrm{kp}, \mathrm{ki})$. In this work, an ISE objective function is considered for the ideal tuning of the PI controller. In CSO-based PI controller tuning, the controller constants (kp,ki) are acclimated to limit the worth of ISE target function and to further develop the time response investigation by lessening peak overshoot and settling time[22,19].

\section{Result and Performance Evaluation:}

The Sustainable Level control Responses of hopper tank were obtained by simulating the closed loop control system using MATLAB Simulink software. The time Integral performances are to optimize the demonstration of hopper tank framework by decreasing the error \& acquiring the finest value. Various error performances are given beneath. 
$\begin{array}{ll}>\text { Integration on squared error } & \text { ISE }=\int E^{2}(t) d t \\ >\text { Integration on absolute error } & \text { IAE }=\int|E(t)| d t\end{array}$

$>$ Integration on time $\&$ absolute error $\quad$ ITAE $=\int \mathrm{t}|\mathrm{E}(\mathrm{t})| \mathrm{dt}$

The system performance is obtained for different regions. Region 1 is said to be the lower region of the conical tank where the area of cross section varies as the height increases. The nominal height is said to be $15 \mathrm{~cm}$ \& Conventional tuning and Cuckoo search Optimization (CSO-PI) based tuning gain values are exposed in Table 4.

Table:4 Tuning controller values of Region 1

\begin{tabular}{|l|l|l|l|}
\hline \multicolumn{6}{|l|}{ REGION 1- $(\mathbf{0}$ to $\mathbf{1 5} \mathbf{~ c m}) ; \boldsymbol{G}_{\mathbf{1}}(\boldsymbol{s})=\frac{\mathbf{0 . 0 3 5 4 2}}{(\mathbf{1 . 5 4 8} \boldsymbol{s}+\mathbf{1})} \boldsymbol{e}^{\mathbf{- 0 . 9 s}}$} \\
\hline S. No & Tuning Method & $\mathbf{K}_{\mathbf{P}}$ & $\mathbf{K}_{\mathbf{i}}$ \\
\hline 1 & ZN-PI & 43.06 & 16.94 \\
\hline 2 & CC-PI & 46.054 & 13.80 \\
\hline 3 & TL- PI & 29.76 & 13.54 \\
\hline 4 & CHR-PI ( Set Point Tracking) & 29.136 & 18.82 \\
\hline 5 & Simple IMC -PI $(\lambda=2)$ & 15.07 & 9.735 \\
\hline 6 & Direct Synthesis-PI & 28.233 & 18.238 \\
\hline 7 & FO-PI & 26.38 & 17.69 \\
\hline 8 & CSO-PI & 29.4338 & 17.1479 \\
\hline
\end{tabular}

The resulting output of Region 1 (Individual region based Level control with Conventional tuning) is exposed in figure 3 . The servo level change of $2 \mathrm{~cm}$ and the load changes are applied to the controller output for various controller techniques.

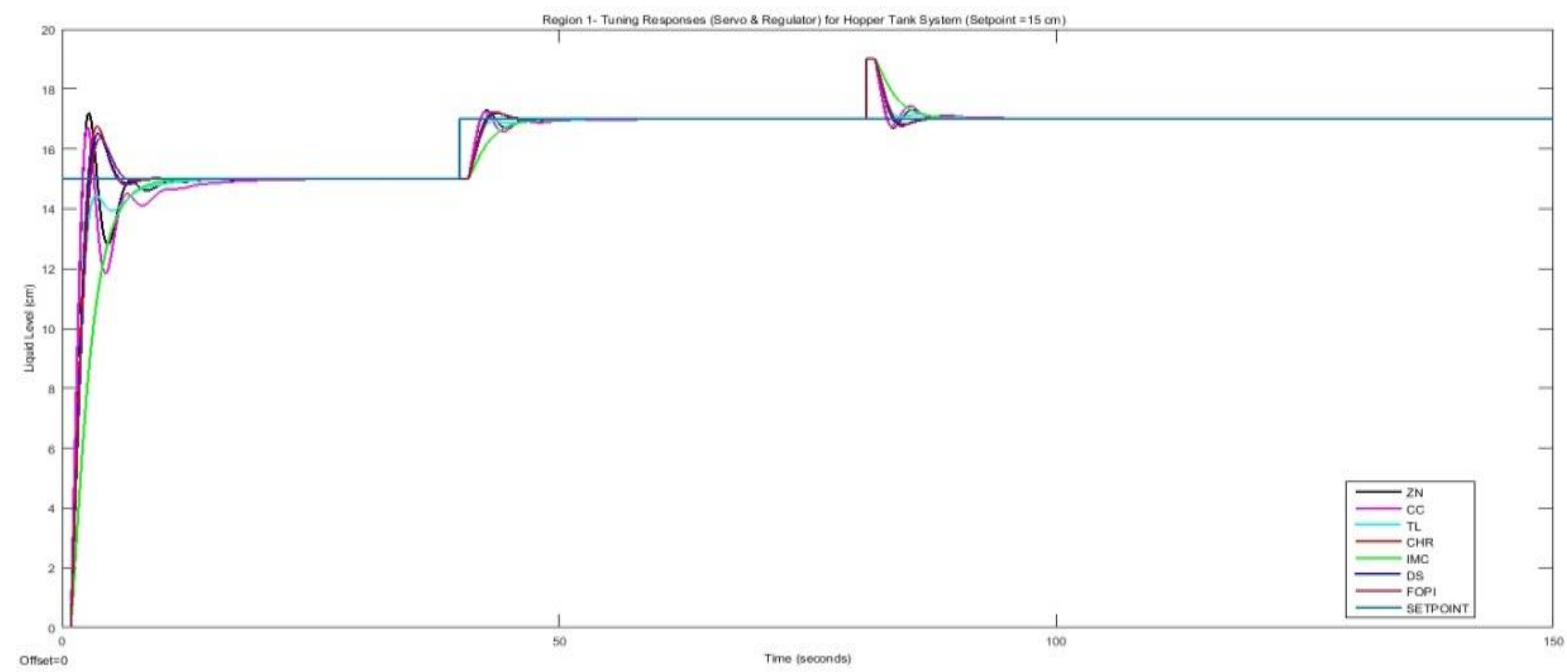

Figure 3. Controlled Process output with servo regulatory responses for Setpoint $=15 \mathrm{~cm}$

For Region1 the performance indices taken by considering Time Domain analysis and time integral criteria were calculated as exposed in table 5, to determine the best suited controller for region based hopper tank design. It states that the CHR method provides the fastest settling time. 
Table:5 Performances Indices for Region 1

\begin{tabular}{|c|c|c|c|c|c|c|}
\hline \multirow{2}{*}{$\begin{array}{c}\text { Tuning } \\
\text { Methods }\end{array}$} & \multicolumn{3}{|c|}{ Time Integral Performances } & \multicolumn{3}{c|}{ Time Domain Analysis Parameters } \\
\cline { 2 - 7 } & ISE & IAE & ITAE & $\begin{array}{c}\text { Settling Time } \\
\text { (Ts) Sec }\end{array}$ & $\begin{array}{c}\text { Peak Overshoot } \\
(\%)\end{array}$ & $\begin{array}{c}\text { Rise Time } \\
\text { (Tr) Sec }\end{array}$ \\
\hline ZN-PI & 293.80 & 29.07 & 41.85 & 9.36 & 14.70 & 0.93 \\
\hline CC-PI & 298 & 33.23 & 81.11 & 12.40 & 11.50 & 0.91 \\
\hline TL-PI & 326 & 31.28 & 42.92 & 8.42 & 0 & 1.61 \\
\hline CHR-PI & 319.90 & 28.42 & 23.45 & 5.12 & 11.70 & 1.31 \\
\hline IMC-PI & 447.30 & 43.50 & 66.46 & 7.98 & 0 & 4.04 \\
\hline DS-PI & 322.90 & 28.53 & 24.77 & 5.21 & 10.10 & 1.36 \\
\hline FO-PI & 331.90 & 29.55 & 25.81 & 5.60 & 9.04 & 1.46 \\
\hline CSO-PI & 318.60 & 26.70 & 20.05 & 4.55 & 6.68 & 1.38 \\
\hline
\end{tabular}

Region 2 is said to be the upper-lower region of the conical portion where the area of cross section varies as the height increases. The nominal height is said to be $30 \mathrm{~cm} \&$ Conventional and CSO based PI controller tuning parameters are publicized in Table 6.

Table:6 Tuning controller values of Region 2

\begin{tabular}{|c|l|c|c|}
\hline \multicolumn{4}{|c|}{ REGION 2- $(\mathbf{1 5}$ to $30 \mathbf{~ c m}) ; \quad G_{\mathbf{2}}(\boldsymbol{s})=\frac{\mathbf{0 . 0 5 0 1 3}}{(\mathbf{8 . 9 1 7 5 s + 1 )}} \boldsymbol{e}^{-\mathbf{4 . 8 s}}$} \\
\hline S. No & \multicolumn{1}{|c|}{ Tuning Method } & $\mathbf{K}_{\mathbf{P}}$ & $\mathbf{K}_{\mathbf{i}}$ \\
\hline 1 & ZN-PI & 32.25 & 2.36 \\
\hline 2 & CC-PI & 35.01 & 1.768 \\
\hline 3 & TL- PI & 22.29 & 1.96 \\
\hline 4 & CHR-PI ( Set Point Tracking) & 22.24 & 2.493 \\
\hline 5 & Simple IMC -PI $(\lambda=8.5)$ & 13.37 & 1.50 \\
\hline 6 & Direct Synthesis-PI & 19.95 & 2.24 \\
\hline 7 & FO-PI & 22.454 & 2.26 \\
\hline 8 & CSO-PI & 22.202 & 2.253 \\
\hline
\end{tabular}

The resulting output of Region 2 (Individual region based fluid Level control through Conventional tuning) is publicized in figure 4 . The servo level change of $5 \mathrm{~cm}$ and the load changes are applied to the controller output for various controller techniques.

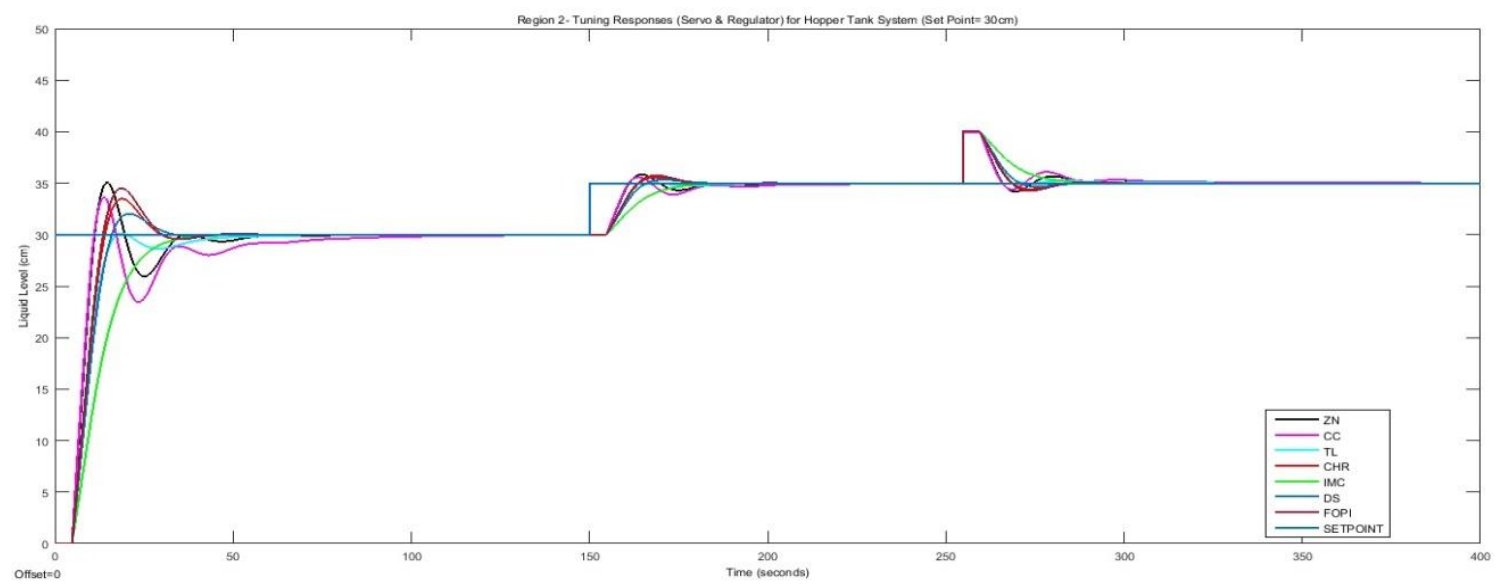

Figure 4. Controlled Process output with servo regulatory responses for Set point $=30 \mathrm{~cm}$ 
For Region 2 the performance indices taken by considering Time domain investigation \& time integral error criteria were calculated as exposed in table 7, to determine the best-suited controller for region based hopper tank design. It states that the Cuckoo method provides the fastest settling time and reduced error values.

Table:7 Performances indices for Region 2

\begin{tabular}{|c|c|c|c|c|c|c|}
\hline \multirow{2}{*}{ Tuning Methods } & \multicolumn{3}{|c|}{ Time Integral Performances } & \multicolumn{2}{c|}{ Time Domain Analysis Parameters } \\
\cline { 2 - 7 } & ISE & IAE & ITAE & $\begin{array}{c}\text { Settling Time } \\
\text { (Ts) Sec }\end{array}$ & $\begin{array}{c}\text { Peak Overshoot } \\
(\%)\end{array}$ & $\begin{array}{c}\text { Rise Time (Tr) } \\
\text { Sec }\end{array}$ \\
\hline ZN-PI & 6288 & 307.9 & 2797 & 49.1 & 16.8 & 4.94 \\
\hline CC-PI & 6400 & 367.5 & 6101 & 69.8 & 12 & 4.81 \\
\hline TL-PI & 6888 & 305.7 & 2249 & 39.9 & 0.413 & 8.04 \\
\hline CHR-PI & 6824 & 302.9 & 1920 & 27.3 & 11.7 & 6.94 \\
\hline IMC-PI & 8657 & 399 & 3192 & 32.5 & 0 & 16.50 \\
\hline DS-PI & 7069 & 306 & 1830 & 28.8 & 6.8 & 8.13 \\
\hline FO-PI & 6836 & 311.7 & 2141 & 28.1 & 15.1 & 6.65 \\
\hline CSO-PI & 6801 & 294 & 1712 & 24.4 & 6.64 & 7.37 \\
\hline
\end{tabular}

Region 3 is said to be the middle region of the conical portion where the area of cross section varies as the height increases. The nominal height is said to be $45 \mathrm{~cm}$ and gain values are exposed with Table 8.

Table:8 Tuning controller values of Region 3

\begin{tabular}{|c|l|c|c|}
\hline \multicolumn{4}{|c|}{ REGION 3- $\left(30\right.$ to 45 cm); $G_{\mathbf{3}}(s)=\frac{0.06170}{(24.572 s+1)} e^{-11.20 s}$} \\
\hline S. No & \multicolumn{1}{|c|}{ Tuning Method } & KP & $\mathbf{K}_{\mathbf{i}}$ \\
\hline 1 & ZN-PI & 30.02 & 0.93 \\
\hline 2 & CC-PI & 33.35 & 0.72 \\
\hline 3 & TL- PI & 20.74 & 0.854 \\
\hline 4 & CHR-PI ( Set Point Tracking) & 21.33 & 0.87 \\
\hline 5 & Simple IMC -PI $(\lambda=20)$ & 12.76 & 0.52 \\
\hline 6 & Direct Synthesis-PI & 16.21 & 0.66 \\
\hline 7 & FO-PI & 19.08 & 0.82 \\
\hline 8 & CSO-PI & 20.978 & 0.776 \\
\hline
\end{tabular}

The resulting output of Region3 (Individual region based Level control with Conventional tuning) is shown in figure 5 . The servo level change of $5 \mathrm{~cm}$ and the load changes are applied to the controller output for various controller techniques.

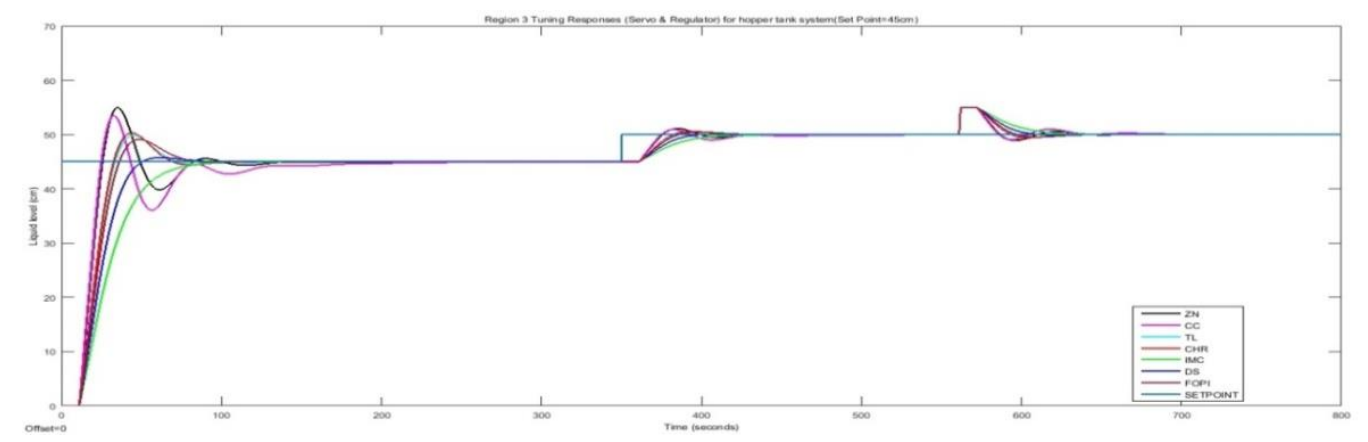

Figure 5. Controlled Process output with servo regulatory responses for Setpoint $=45 \mathrm{~cm}$ 
For Region3 the estimation indices taken by in view of time domain study \& time integral criteria were calculated as exposed in table 9, to determine the best suited controller for region based hopper tank design. It states that the CSO-PI method provides the fastest settling time.

Table:9 Performances indices for Region 3

\begin{tabular}{|c|c|c|c|c|c|c|}
\hline \multirow{2}{*}{$\begin{array}{c}\text { Tuning } \\
\text { Methods }\end{array}$} & \multicolumn{3}{|c|}{ Time Integral Performances } & \multicolumn{2}{c|}{ Time Domain Analysis Parameters } \\
\cline { 2 - 7 } & ISE & IAE & ITAE & $\begin{array}{c}\text { Settling Time } \\
\text { (Ts) Sec }\end{array}$ & $\begin{array}{c}\text { Peak } \\
\text { Overshoot (\%) }\end{array}$ & $\begin{array}{c}\text { Rise Time } \\
\text { (Tr) Sec }\end{array}$ \\
\hline ZN-PI & 33470 & 1090 & 22240 & 78.3 & 22.10 & 11.4 \\
\hline CC-PI & 33320 & 1213 & 39510 & 126 & 18.9 & 10.7 \\
\hline TL-PI & 36140 & 1066 & 16890 & 65.5 & 10.8 & 16.8 \\
\hline CHR-PI & 35840 & 1062 & 16440 & 63.8 & 11.8 & 16.2 \\
\hline IMC-PI & 45590 & 1403 & 27260 & 76.5 & 0.0009 & 38.8 \\
\hline DS-PI & 39800 & 1142 & 16700 & 66.5 & 1.64 & 25 \\
\hline FO-PI & 37150 & 1097 & 17210 & 72.10 & 9.16 & 18.4 \\
\hline CSO-PI & 35790 & 1037 & 15440 & 57.5 & 6.48 & 17.4 \\
\hline
\end{tabular}

Region 4 is said to be the lower- top region of the conical portion or middle region of hopper tank where the area of cross section varies as the height increases. The nominal height is said to be $60 \mathrm{~cm} \&$ gain values are revealed with Table 10.

Table:10 Tuning controller values of Region 4

\begin{tabular}{|c|l|l|c|}
\hline \multicolumn{4}{|c|}{ REGION 4- (45 to 60 cm); $G_{\mathbf{4}}(\boldsymbol{s})=\frac{\mathbf{0 . 0 7 1 3 0}}{(\mathbf{5 0 . 0 3 s + 1})} \boldsymbol{e}^{-\mathbf{1 9 . 5 0 s}}$} \\
\hline S. No & \multicolumn{1}{|c|}{ Tuning Method } & $\mathbf{K}_{\mathbf{P}}$ & $\mathbf{K}_{\mathbf{i}}$ \\
\hline 1 & ZN-PI & 29.67 & 0.511 \\
\hline 2 & CC-PI & 33.55 & 0.362 \\
\hline 3 & TL- PI & 20.51 & 0.441 \\
\hline 4 & CHR-PI ( Set Point Tracking) & 21.59 & 0.432 \\
\hline 5 & Simple IMC -PI $(\lambda=35)$ & 12.88 & 0.26 \\
\hline 6 & Direct Synthesis-PI & 14.03 & 0.28 \\
\hline 7 & FO-PI & 19.75 & 0.401 \\
\hline 8 & CSO-PI & 19.9476 & 0.36004 \\
\hline
\end{tabular}

The resulting output of Region 4(Individual region based Level control with Conventional tuning) is shown in figure 6 . The servo level change of $10 \mathrm{~cm}$ and the load changes are applied to the controller output for various controller techniques.

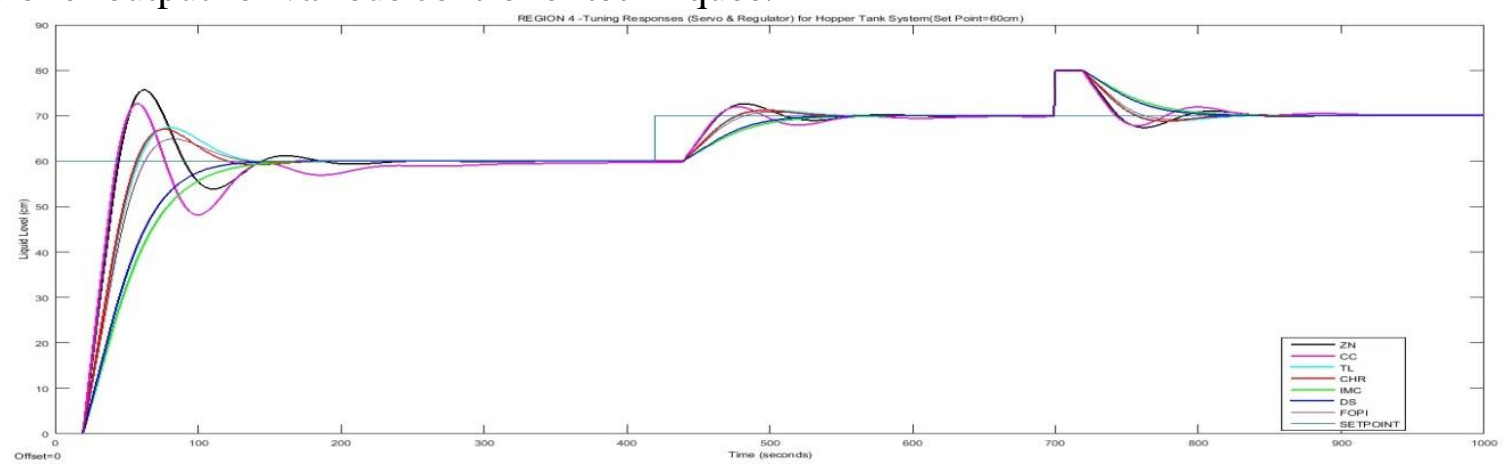

Figure 6. Controlled Process output with servo regulatory responses for Setpoint $=60 \mathrm{~cm}$ For Region4 the performance indices taken by considering Time Domain analysis and time integral criteria were calculated as exposed in table 11, to determine the best suited controller for 
region based hopper tank design. It states that the CSO-PI method provides the fastest settling time.

Table:11 Performances indices for Region 4

\begin{tabular}{|c|c|c|c|c|c|c|}
\hline \multirow{2}{*}{$\begin{array}{c}\text { Tuning } \\
\text { Methods }\end{array}$} & \multicolumn{2}{|c|}{ Time Integral Performances } & \multicolumn{2}{c|}{ Time Domain Analysis Parameters } \\
\cline { 2 - 7 } & ISE & IAE & ITAE & $\begin{array}{c}\text { Settling Time } \\
\text { (Ts) Sec }\end{array}$ & $\begin{array}{c}\text { Peak Overshoot } \\
\text { (\%) }\end{array}$ & $\begin{array}{c}\text { Rise Time } \\
\text { (Tr) Sec }\end{array}$ \\
\hline ZN-PI & $1.054 \mathrm{e}^{+5}$ & 2601 & $9.369 \mathrm{e}^{+5}$ & 162 & 26.2 & 19.6 \\
\hline CC-PI & $1.038 \mathrm{e}^{+5}$ & 2872 & $1.728 \mathrm{e}^{+5}$ & 225 & 21.1 & 18.6 \\
\hline TL-PI & $1.130 \mathrm{e}^{+5}$ & 2545 & $7.332 \mathrm{e}^{+5}$ & 122 & 12.4 & 29.3 \\
\hline CHR-PI & $1.109 \mathrm{e}^{+5}$ & 2463 & $6.722 \mathrm{e}^{+5}$ & 111 & 11.7 & 28.2 \\
\hline IMC-PI & $1.411 \mathrm{e}^{+5}$ & 3242 & $1.097 \mathrm{e}^{+5}$ & 130 & 0.05 & 67 \\
\hline DS-PI & $1.344 \mathrm{e}^{+5}$ & 3005 & $9.067 \mathrm{e}^{+5}$ & 113 & 0 & 58.1 \\
\hline FO-PI & $1.141 \mathrm{e}^{+5}$ & 2492 & $6.586 \mathrm{e}^{+5}$ & 118 & 8.5 & 31.9 \\
\hline CSO-PI & $1.098 \mathrm{e}^{+5}$ & 2355 & $6.387 \mathrm{e}^{+4}$ & 97.4 & 3.76 & 33.4 \\
\hline
\end{tabular}

Region 5 is said to be the upper region of the hopper tank were the area of cross section remains as the height increases. The nominal height is said to be $100 \mathrm{~cm} \&$ gain values (Conventional and Soft computing based) are exposed in Table: 12

Table: 12 Tuning controller values of Region 5

\begin{tabular}{|c|l|l|c|}
\hline \multicolumn{4}{|c|}{ REGION 5- $(60$ to $100 \mathrm{~cm}) ; \quad G_{\mathbf{5}}(\boldsymbol{s})=\frac{\mathbf{0 . 0 9 2 0}}{\mathbf{6 5 . 0 2 9} \boldsymbol{s}+\mathbf{1})} \boldsymbol{e}^{-\mathbf{2 4 . 2 5} \boldsymbol{s}}$} \\
\hline S. No & \multicolumn{1}{|c|}{ Tuning Method } & \multicolumn{1}{|c|}{$\mathbf{K}_{\mathbf{i}}$} \\
\hline 1 & ZN-PI & 23.913 & 0.34 \\
\hline 2 & CC-PI & 27.14 & 0.35 \\
\hline 3 & TL- PI & 16.53 & 0.19 \\
\hline 4 & CHR-PI ( Set Point Tracking) & 17.49 & 0.27 \\
\hline 5 & Simple IMC -PI $(\lambda=43)$ & 10.51 & 0.16 \\
\hline 6 & Direct Synthesis-PI & 10.87 & 0.17 \\
\hline 7 & FO-PI & 15.42 & 0.235 \\
\hline 8 & CSO-PI & 16.5522 & 0.2317 \\
\hline
\end{tabular}

The resulting output of Region 5 (Individual region based Level control with Conventional tuning) is shown in figure 7 . The servo level change of $20 \mathrm{~cm}$ and the load changes are applied to the controller output for various controller techniques.

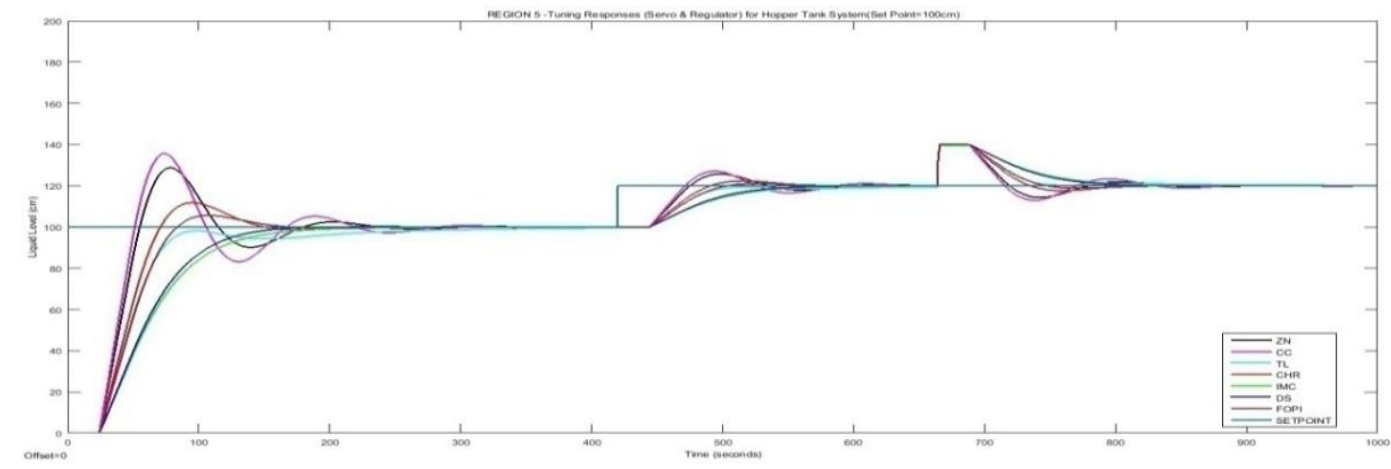

Figure 7. Controlled Process output with servo regulatory response for Setpoint $=100 \mathrm{~cm}$ 
For Region 5 the performance indices taken by considering Time Domain analysis and time integral criteria were calculated as exposed in table 13, to determine the best suited controller for region based hopper tank design. It states that the CSO-PI method provides the fastest settling time with minimum error when comparing with conventional tuning methods

Table:13 Performances indices for Region 5

\begin{tabular}{|c|c|c|c|c|c|c|}
\hline \multirow{2}{*}{$\begin{array}{c}\text { Tuning } \\
\text { Methods }\end{array}$} & \multicolumn{2}{|c|}{ Time Integral Performances } & \multicolumn{2}{c|}{ Time Domain Analysis Parameters } \\
\cline { 2 - 7 } & ISE & IAE & ITAE & $\begin{array}{c}\text { Settling Time } \\
\text { (Ts) Sec }\end{array}$ & $\begin{array}{c}\text { Peak } \\
\text { Overshoot (\%) }\end{array}$ & $\begin{array}{c}\text { Rise Time } \\
\text { (Tr) Sec }\end{array}$ \\
\hline ZN-PI & $3.688 \mathrm{e}^{+5}$ & 5613 & $2.536 \mathrm{e}^{+5}$ & 214 & 28.8 & 24.2 \\
\hline CC-PI & $3.737 \mathrm{e}^{+5}$ & 5932 & $3.244 \mathrm{e}^{+5}$ & 261 & 35.6 & 21.5 \\
\hline TL-PI & $3.972 \mathrm{e}^{+5}$ & 5721 & $3.112 \mathrm{e}^{+5}$ & 254 & 0 & 44.5 \\
\hline CHR-PI & $3.832 \mathrm{e}^{+5}$ & 5110 & $1.745 \mathrm{e}^{+5}$ & 138 & 11.8 & 35 \\
\hline IMC-PI & $4.873 \mathrm{e}^{+5}$ & 6793 & $2.978 \mathrm{e}^{+5}$ & 171 & 0 & 84.7 \\
\hline DS-PI & $4.748 \mathrm{e}^{+5}$ & 6439 & $2.564 \mathrm{e}^{+5}$ & 147 & 0.199 & 76.7 \\
\hline FO-PI & $3.996 \mathrm{e}^{+5}$ & 5159 & $1.640 \mathrm{e}^{+5}$ & 144 & 5.70 & 42.40 \\
\hline CSO-PI & $3.880 \mathrm{e}^{+5}$ & 5050 & $1.524 \mathrm{e}^{+5}$ & 125 & 5.22 & 39.7 \\
\hline
\end{tabular}

In the region 5 Response, $\mathrm{ZN}$ and $\mathrm{CC}$ tuning methods provide the overshoot 28.8 and 35.6 respectively, while selecting the Setpoint as $100 \mathrm{~cm}$. These overshoots produce an overflow of liquid when the maximum height of the tank is $120 \mathrm{~cm}$. These overshoots would be reduced from 28.8 to 13.38 and 35.6 to 14.08 with the help of Combined Region-based level control which combines the model from region 1 to region 5 to control level in the region5. Combined Regionbased Level Control with servo and regulatory responses for Operating Region $5($ Setpoint $=100 \mathrm{~cm})$ is represented in figure 8 .

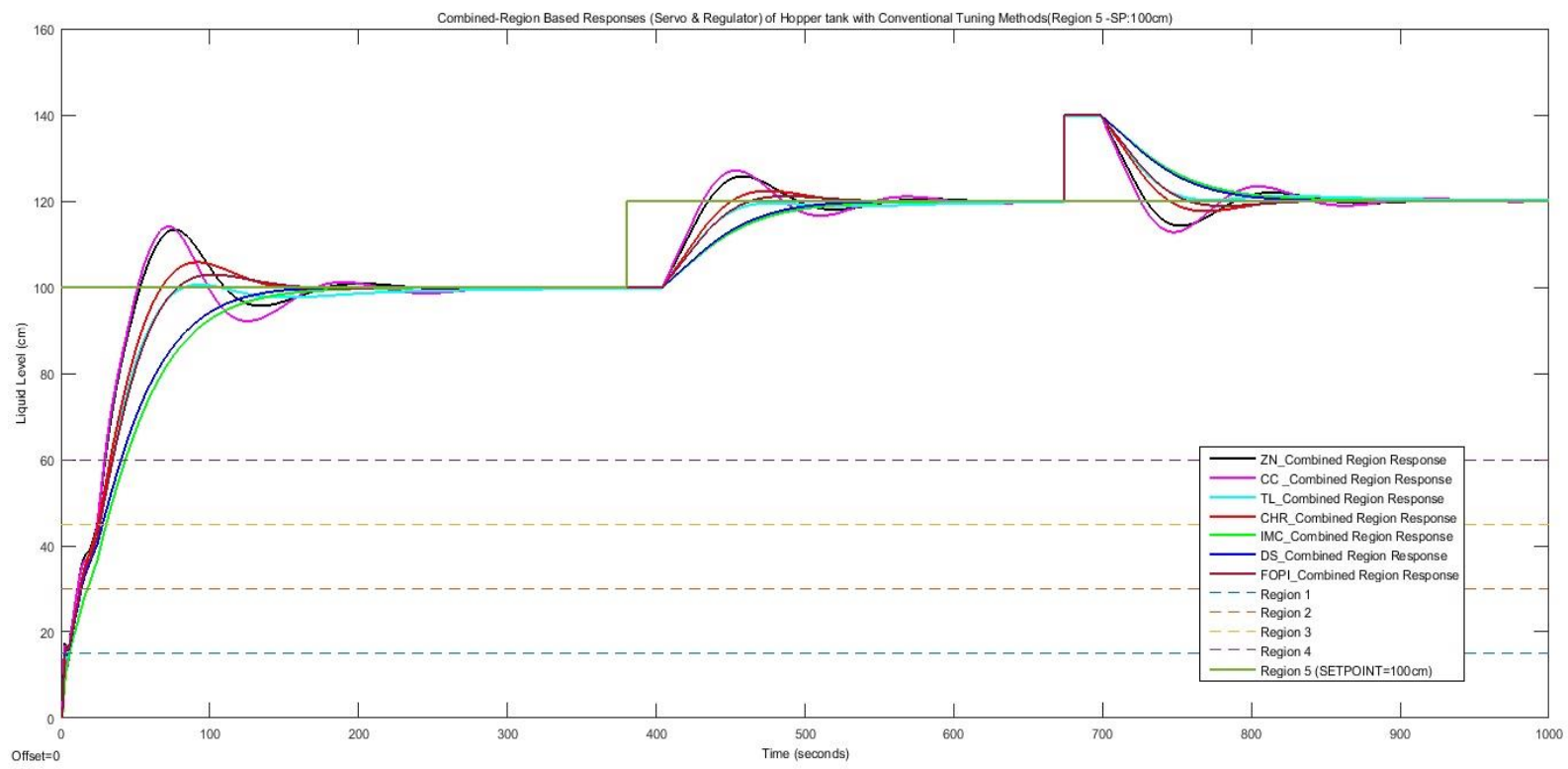

Figure 8. Combined Region based Level Control Responses for Set point $=100 \mathrm{~cm}$

Similarly Settling time and Time integral parameters are also minimized while comparing with Individual region-based level control using conventional tuning rules \& CSO which is shown in table 14. 
Table:14 Combined Region Level Control Performances indices for Region 5(SP=100cm)

\begin{tabular}{|c|c|c|c|c|c|c|}
\hline \multirow{3}{*}{$\begin{array}{l}\text { Tuning } \\
\text { Methods }\end{array}$} & \multicolumn{6}{|c|}{ Combined Region based Level Control for Region 5} \\
\hline & \multicolumn{3}{|c|}{ Time Integral Performances } & \multicolumn{3}{|c|}{ Time Domain Analysis Parameters } \\
\hline & ISE & IAE & ITAE & $\begin{array}{c}\text { Settling } \\
\text { Time (Ts) } \\
\text { Sec }\end{array}$ & $\begin{array}{c}\text { Peak } \\
\text { Overshoot } \\
(\%)\end{array}$ & $\begin{array}{c}\text { Rise Time } \\
\text { (Tr) Sec }\end{array}$ \\
\hline ZN-PI & 59000 & 2205 & $1.015 \mathrm{e}^{+5}$ & 160 & 13.38 & 44 \\
\hline CC-PI & 59790 & 2373 & $1.298 \mathrm{e}^{+5}$ & 161 & 14.08 & 43.61 \\
\hline TL-PI & 63550 & 2288 & $1.245 \mathrm{e}^{+5}$ & 177 & 0.5 & 56.79 \\
\hline CHR-PI & 61310 & 2044 & 63770 & 123 & 5.79 & 53 \\
\hline IMC-PI & 77960 & 2717 & $1.191 \mathrm{e}^{+5}$ & 140 & 0 & 139 \\
\hline DS-PI & 75960 & 2576 & $1.026 \mathrm{e}^{+5}$ & 127 & 0.077 & 83 \\
\hline FO-PI & 63930 & 2063 & 65580 & 124 & 2.95 & 58 \\
\hline CSO-PI & 62390 & 2024 & 62860 & 105.58 & 3.05 & 51.078 \\
\hline
\end{tabular}

The Different Individual region-based level control responses using Cuckoo Search Optimization (CSO) tuning techniques was publicized in Figure 9. The fastest settling time after applying servo changes \& regulator changes could be evaluated using CSO technique.

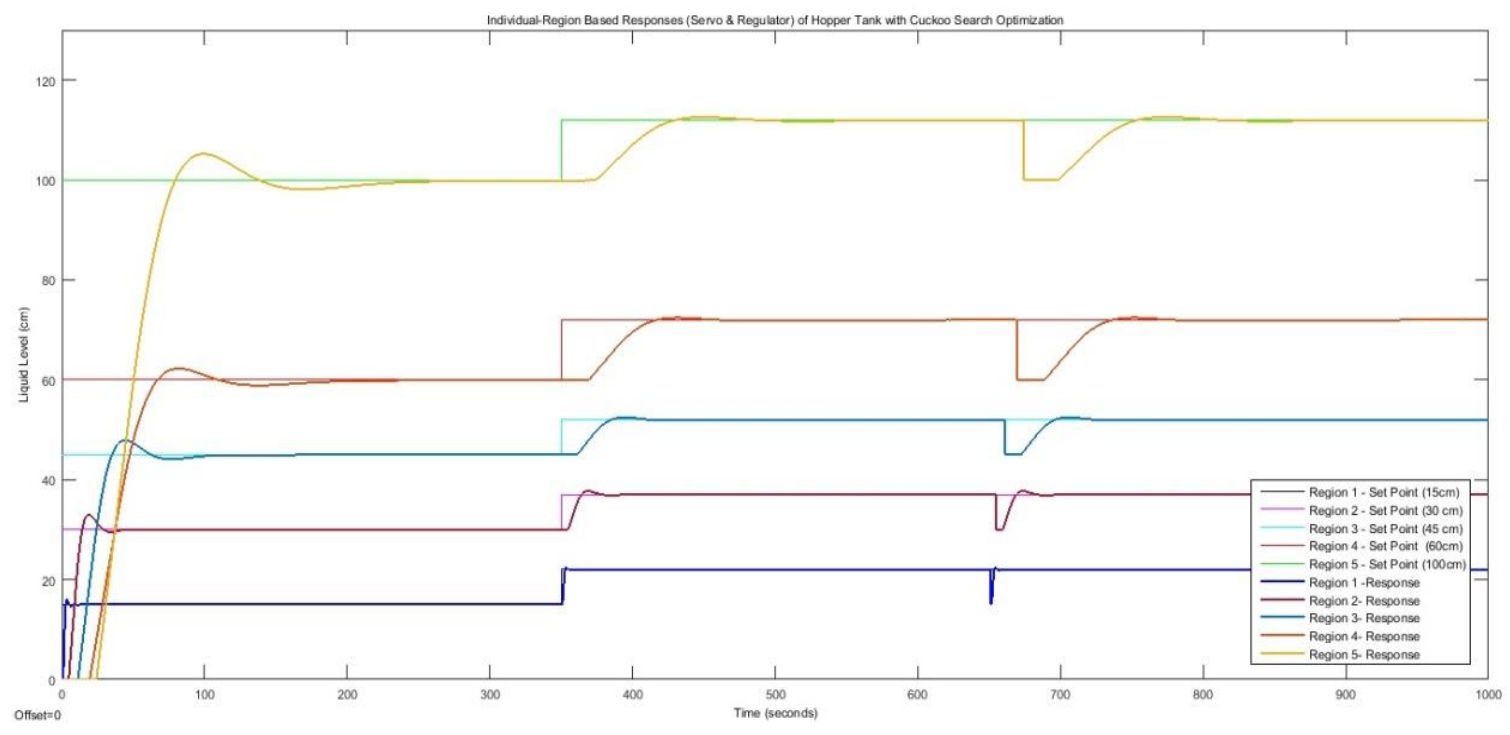

Figure 9. Individual Region based Level Control Responses with CSO-PI

Combined Region-based Level Control with servo and regulatory responses for Operating Region $5($ Set point $=100 \mathrm{~cm})$ is represented in figure 10 . Error integral values and settling times were reduced with the help of Combined Region-based level control which combines the model from region 1 to region 5 to control level in the region 5. For both the Individual and Combined region-based performance analysis, it undoubtedly pointed out that CSO-PI provides Minimum Settling time and reduced Time Integral error values while comparing with all Conventional tuning methods like CHR, TL,IMC, ZN,FO ect. 




Figure 10.Servo Regulatory Response of Combined Region for set point of $100 \mathrm{~cm}$ with CSO-PI

The Comparative analysis of Settling time and IAE Error value for all five regions (Conventional tuning \&Cuckoo-PI) with the help of bar chart representation is shown in figures 11 and 12 respectively. It states that the combined region-based level control with Cuckoo Search Optimization-PI controller achieves Minimized time indices parameters when compared with all individual region-based level control with Conventional tuning methods of the hopper tank.
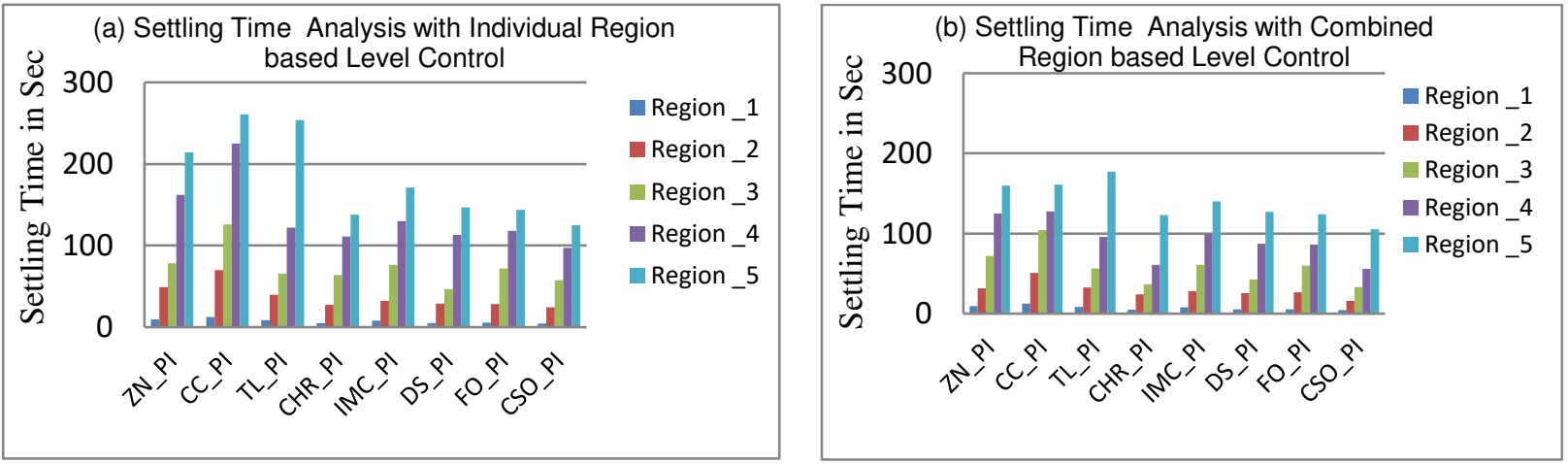

Figure 11. Settling Time Analysis with (a) Individual Region based Level Control (b) Combined Region based Level Control
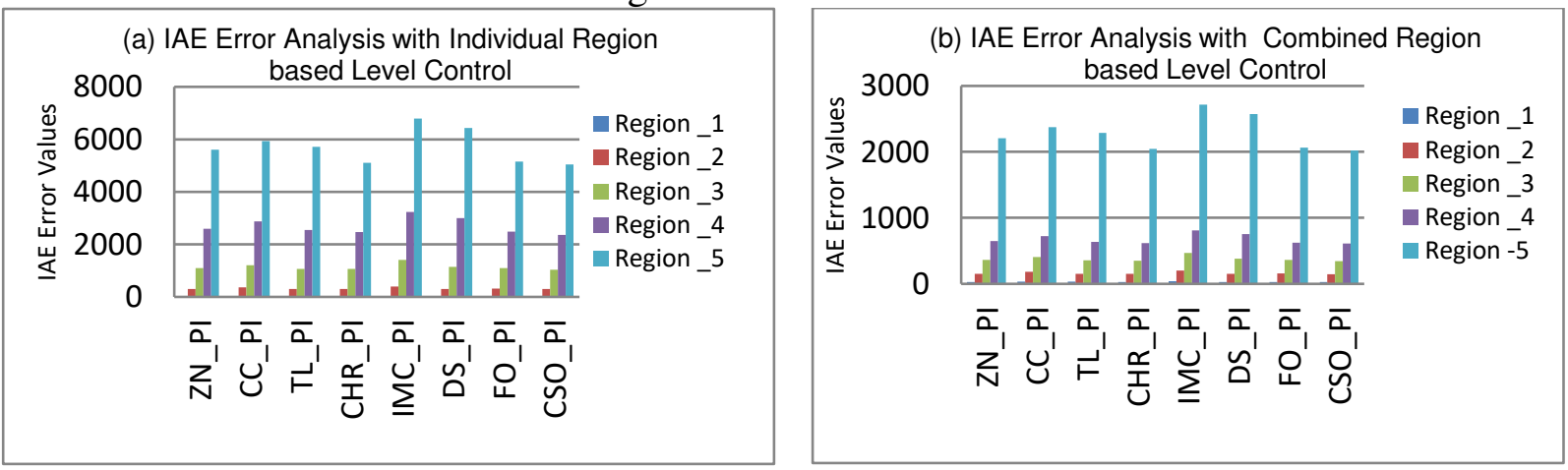

Figure 12. IAE Error Analysis with (a) Individual Region based Level Control (b) Combined Region based Level Control. 


\section{Conclusion:}

Detailed research work was carried out to realize and investigate the nonlinear process tank which is used in the wastewater treatment plants. The nonlinear process considered was a hopper tank system \& its transfer function was developed based on the linearization method by considering various regions. The Matlab Simulations were carried out using Simulink model. It can be concluded that the PI controller can be used for the nonlinear Hopper tank to control and maintain the sustainable Liquid level. Comparisons based on seven different conventional tuning Controller methods (ZN, CC, TL, CHR, IMC, DS \&FOPI) and Soft computing approach (Cuckoo Search Optimization algorithm) are used to sustain the liquid level of tank for different operating ranges and nominal values. Depending on the Time integral performance criteria and time-domain analysis it was concluded that the CSO-PI method provides better Sustainable performance when compared with other Conventional Controller tuning methods. In the region 5 responses (Set point $=100 \mathrm{~cm}$ ), the minimum settling time of $125 \mathrm{secs}$ is achieved by the Cuckoo Search Optimization (CSO-PI) tuning method while other conventional tuning methods having a range from $138 \mathrm{secs}$ to $261 \mathrm{secs}$. The minimum settling time $(4.55,24.4,57.4 \& 97.4 \mathrm{sec})$ is achieved in all other regions also (for Set points $15 \mathrm{~cm}, 30 \mathrm{~cm}, 45 \mathrm{~cm} \& 60 \mathrm{~cm}$ ). On another side with the help of combined region-based CSO-PI level control, Peak Overshoot and settling time are minimized from $5.22 \%$ to $3.05 \%$ and $125 \mathrm{secs}$ to $105.58 \mathrm{secs}$ respectively for the set point at $100 \mathrm{~cm}$. On comparing the performance metrics achieved, it was identified that the Combined Region-based Level Control technique gives a better result as compared to the Individual Region level control technique. So the Cuckoo Search Optimization based PI controller (CSO-PI) optimal tuning method provides the Fastest Settling time with reduce Peak Overshoot moreover the error is also reduced to provide better performance of Hopper tank Level Control System.

Ethics approval and consent to participate: Not applicable.

Funding: Not applicable.

Conflict of interests: The authors declare that they have no conflict of interests.

Informed Consent: Not applicable

Authors' contributions: All authors discussed the results and implications and commented on the manuscript at all stages. All authors read and approved the final manuscript for publication.

\section{References:}

1. Dhanalakshmi, R., and R. Vinodha. "Design of control schemes to adapt PI controller for conical tank process." Int. J. Advance. Soft Comput. Appl 5.3 (2013): 1-20.

2. Vadivazhagi, S., and $\operatorname{Dr} \mathrm{N}$. Jaya. "Modelling and Simulation of Interacting Conical Tank Systems." International Journal of Innovative Research in Science, Engineering and Technology 3.6 (2014).

3. Kala, H., P. Aravind, and M. Valluvan. "Comparative analysis of different controller for a nonlinear level control process." 2013 IEEE Conference on Information \& Communication Technologies. IEEE, 2013. 
4. Anand, S., V. Aswin, and S. Rakesh Kumar. "Simple tuned adaptive PI controller for conical tank process." 2011 International Conference on Recent Advancements In Electrical, Electronics And Control Engineering. IEEE, 2011.

5. Saravanakumar, G., Dinesh, S., Preteep, S., \& Sridhar, P. "Controller tuning method for non-linear conical tank system." Asian Journal of Applied Science and Technology (AJAST) 1.2 (2017): 224-228.

6. Sarif, B. Mabu, DV Ashok Kumar, and M. Venu Gopala Rao. "Comparison Study of PID Controller Tuning using Classical/Analytical Methods." International Journal of Applied Engineering Research 13.8 (2018): 5618-5625.

7. Marshiana, D., and P. Thirusakthimurugan. "Fractional order PI controller for nonlinear systems." 2014 International Conference on Control, Instrumentation, Communication and Computational Technologies (ICCICCT). IEEE, 2014.

8. Venkatesan, M., and V. R. Ravi. "Sliding mode observer based sliding mode controller for interacting nonlinear system." Second International Conference on Current Trends In Engineering and TechnologyICCTET 2014. IEEE, 2014.

9. Ravi, V. R., and T. Thyagarajan. "A decentralized PID controller for interacting non linear systems." 2011 International Conference on Emerging Trends in Electrical and Computer Technology. IEEE, 2011.

10. Ravi, V. R., and T. Thyagarajan. "Application of adaptive control technique to interacting Non Linear Systems." 2011 3rd International Conference on Electronics Computer Technology. Vol. 2. IEEE, 2011.

11. Ravi, V. R., T. Thyagarajan, and M. Monika Darshini. "A multiple model adaptive control strategy for model predictive controller for interacting non linear systems." 2011 International Conference on Process Automation, Control and Computing. IEEE, 2011.

12. Ravi, V. R., and T. Thyagarajan. "Adaptive decentralized PI controller for two conical tank interacting level system." Arabian Journal for Science and Engineering 39.12 (2014): 8433-8451.

13. Marshiana, D., and P. Thirusakthimurugan. "Design of Deadbeat Algorithm for a Nonlinear Conical tank system." Procedia Computer Science 57 (2015): 1351-1358.

14. Marshiana, D., and P. Thirusakthimurugan. "Control of level in chemical industry for a nonlinear conical tank process." Research Journal of Pharmaceutical Biological and Chemical Sciences 6(3) (2015): 1322-1328.

15. Anandanatarajan, R., M. Chidambaram, and T. Jayasingh. "Limitations of a PI controller for a first-order nonlinear process with dead time." ISA transactions 45.2 (2006): 185-199.

16. Kesavan, Suresh Manic, T. V. N. Padmesh, and CHAN WOEI Shyan. "Controller tuning for nonlinear hopper process tank-a real time analysis." Journal of Engineering Science and Technology 9 (2014): 59-67.

17. Murugananthan, V., M. Valluvan, and G. Sakthivel. "Level Control of Hopper Tank Process Using ModelBased Controller." Electronic Systems and Intelligent Computing. Springer, Singapore, 2020. 453-463.

18. Gireesh, N., and G. Sreenivasulu. "Comparison of PI controller performances for a Conical Tank process using different tuning methods." 2014 International Conference on Advances in Electrical Engineering (ICAEE). IEEE, 2014.

19. Durga Vivek and Dr.P. Bharath kumar. "PID Controller Design with Cuckoo Search Algorithm for Stable and Unstable SOPDT Processes”. IOP Conf. Ser.: Mater. Sci. Eng., 1091 (2021): 012059

20. Saeed Balochain, Eshagh Ebrahimi, Parameter Optimization via Cuckoo Optimization Algorithm of Fuzzy Controller for Liquid level Control", Journal of Engineering, vol. 2013, (2013): 1-7.

21. M. Kishnani, S. Pareek and R. Gupta, "Optimal Tuning of PID controller by Cuckoo Search via Lévy flights," 2014 International Conference on Advances in Engineering \& Technology Research, (2014): 1-5.

22. Petchinathan Govindan," Evolutionary algorithms based tuning of PID controller for an AVR system", International Journal of Electrical and Computer Engineering. 10(3) (2020): 3047-3056.

23. A.Y. Abdelaziz, E.S. Ali, "Cuckoo Search algorithm based load frequency controller design for nonlinear interconnected power system", Electrical Power and Energy Systems, 73 (2015): 632-643.

24. D.Marshiana, P.Thirusakthimurugan, "Optimization of a non-linear conical tank system using Cuckoo algorithm for Pharmaceutical industries”, Biomedical Research, 28 (6) (2017): 2778-2782. 